\title{
Enseñar (el afuera de) el arte a partir de Deleuze
}

\section{Adolfo Chaparro Amaya Universidad del Rosario}

La filosofía de Deleuze se ha caracterizado por rupturas señaladas con formas tradicionales de interpretar la historia de la filosofía. Es famosa la lectura que hace de autores canónicos con resultados que los vuelven irreconocibles para sus exegetas. Es el caso de sus libros sobre Spinoza y Leibniz, y en cierta medida los estudios que realizara acerca de Nietzsche, Bergson y Kant. En todos ellos rige la premisa de que la lectura ni es ingenua ni pretende rescatar un núcleo de verdad que hubiera permanecido en la tradición, sino más bien la idea de que al confrontar esa tradición con el plano de consistencia donde se despliega el pensamiento de Deleuze, el filósofo leído es sometido a un prueba tal que termina por producir un tercero que no estaba en la tradición ni el pensamiento inicial del propio Deleuze. Esos pequeños monstruos de la filosofía han terminado por crear una nueva manera de aproximarse a los textos canónicos y, en la consideración retrospectiva del conjunto de la obra de Deleuze, otra manera de hacer historia de la filosofía.

Ese principio de diferenciación también afecta la arquitectónica en la que tradicionalmente se ha establecido la filosofía como un campo de diversas disciplinas en las que reconocemos la ética, la estética, la epistemología y las maneras de hacer filosofía 'de', esto es, filosofías que surgen en el desarrollo de las más diversas ciencias. Aunque en una aproximación a la estética uno podría pensar que Deleuze simplemente no considera pertinente esa división en el campo de la filosofía, en realidad lo que surge es una nueva distribución del campo a partir de una muy estricta consideración del concepto como lo propio de la filosofía, del percepto como lo propio del arte y del functor como lo propio de la ciencia. Aunque hay otras entradas a la filosofía del arte en Deleuze, siguiendo el texto pedagógico escrito con Guattari Qué es la filosofía, tendríamos que en principio el problema del arte estaría separado de la pregunta tradicional por la estética como ciencia 
de los sentidos, y tendría como exigencia la posibilidad de dar cuenta de lo que aparece en la singularidad de la obra de arte.

Frente a esta separación del campo del arte del de la estética, inmediatamente aparecen los textos en los que Deleuze se ocupó de la estética y, además, la diversidad de conceptos -pliegue, figura, simulacro, repetición y diferencia, ritornello, literatura menor, imagen-tiempo, imagen-movimiento, entre otros-que compiten con el de percepto como herramienta privilegiada para la aproximación a la obra de arte. Se abre así una perspectiva fronteriza en la que el rechazo a la estética tradicional se compensa en Deleuze con la creación de una constelación de conceptos en los que no parece tanto interesado en la obra de arte como en hacer de la realidad una forma de expresión artística. Se podría mostrar que si bien el percepto pone a punto su preocupación un poco 'añeja' por la pintura, este concepto y todos los otros mencionados han estado a la base de las últimas corrientes del arte contemporáneo. La hipótesis es que en el mismo movimiento por el cual el arte sale de sí mismo y cuestiona radicalmente la idea de 'obra' para descubrirse en los afectos, la materia, el flujo del lenguaje, los flujos energéticos, la experimentación científica, chamánica, política y más profundamente subjetiva, en ese mismo movimiento, Deleuze pareciera volver al terreno de una estética investida por la ontología como si finalmente ese fuera el punto de llegada de su filosofía.

Una mirada relativa al arte pictórico, al que por cierta costumbre hemos terminado por adjudicarle el monopolio de la noción misma de arte, abre un primer repertorio de conceptos y de reinterpretaciones de dichos conceptos. Lo interesante es el procedimiento por el cual la singularidad de la obra de Francis Bacon lleva a Deleuze a constituir un punto de vista desde donde volver a leer los grandes ejes estilísticos de la historia del arte: abstracto, figurativo, expresivo, como si esas opciones con sus mezclas y variaciones estilísticas agotaran el conjunto de lo 'pintable'; y como si hubieran existido virtualmente desde el comienzo de la historia de las artes plásticas. Varias consecuencias de aquí. La primera es que no hay una jerarquía entre estos estilos y tampoco la posibilidad de establecer un punto de vista evolutivo epocal según el cual las obras de arte se irían perfeccionando a medida que se perfecciona una técnica o la maestría en un estilo 
determinado. La otra consecuencia es que siempre hay un territorio donde la aproximación filosófica a un artista, en este caso Bacon, es también una pregunta por los criterios, los tiempos, las relaciones con el 'afuera' en la historia de la pintura. Por eso, aunque Deleuze no se ocupara del problema, esa actualización le permite responder oblicuamente al hecho de que la pintura en la segunda mitad del siglo XX pareciera destinada a ceder su lugar como forma de representación a las artes plásticas como formas de presentación. Una forma de leer el Bacon de Deleuze puede, entonces, insistir en su anacronismo o aceptar que, al menos desde el punto de vista estilístico, no matérico ni performativo, probablemente todas las obras de arte siguen siendo una mezcla particular de lo figurativo, lo abstracto y lo expresivo.

En ese ejercicio de cambio de perspectiva en la consideración de la historia del arte, lo más importante para Deleuze era construir conceptos propios que estuvieran claramente ligados a la obra de Bacon, los cuales no deberían perder la singularidad de su origen y, sin embargo, deberían tener la potencia de infinitud con que Deleuze concibió desde un comienzo el concepto de concepto. Así, tenemos nociones que van constituyendo como conceptos tales como 'fuerzas, diagrama, háptico', entre los más importantes. El primero lo podemos referir directamente a Nietzsche aunque no se agote allí. El concepto de diagrama pareciera estar inspirado en la filosofía de Foucault en tanto evoca una cierta estructura que contiene y hace visibles las fuerzas productivas o los discursos de una época, pero en este caso el diagrama lo que hace es mostrar la forma como las fuerzas, los afectos, las imágenes que lo atraviesan son ex-presadas por el pintor. Puede ser que en la pintura renacentista las fuerzas más evidentes, como las de peso, luz y gravedad, se hubieran resuelto en relación con un paradigma perceptivo que tiende a instaurarse como un diagrama canónico organizado en torno a la línea de fuga y a la perspectiva como forma de organización de lo visible. Pero esa es apenas una opción desde el punto de vista que ofrecen las evoluciones y las involuciones de una historia 'multicultural' del arte. Justamente, lo que hace la pintura después del siglo XIX es plantear diagramas que no dependen de la adecuada representación que hacen del mundo visible sino de una organización en la que la pulsión, el deseo o el mundo 'interior' del artista se hace 
indiscernible con el afuera que constituye el motivo de la pintura. En relación con lo háptico diríamos que se trata de una verdadera invención de Deleuze. Es obvio que la pintura moderna le da un valor semejante a la pintura como figura y como materia. En el primer caso los colores terminan por establecer un orden visual que se refleja en la retina de los espectadores, y se traduce en formas, personajes, horizontes, movimientos. En el segundo, se trata de explorar un afuera matérico de la pintura que estaba invisibilizado por las reglas el oficio y que deja huella en relación con el ejercicio mismo de la pincelada. Pero también con toda clase de intervenciones, borraduras, superposiciones, manchas, incluso objetos y papeles superpuestos por arte del collage, que no tienen que ver con un orden figurativo del color sino más bien con la expresión háptica del caos que surge de una renuncia más o menos deliberada a convertir la pintura en un ejercicio representativo.

Otro ámbito de creación conceptual, imposible de desarrollar aquí en detalle, es el que despliega Deleuze en relación con la historia del cine. Vale la pena, sin embargo, señalar la operación por la cual los dos períodos reconocibles de la historia del cine, clásico y moderno, son reducidos por Deleuze a dos grandes dimensiones ontológicas de la imagen. De una parte, la imagen-movimiento, que corresponde a la forma en la que la máquina de visión registra y organiza finalmente la película como una secuencia de acciones que tienen lugar en un determinado espacio-tiempo. Podríamos recordar cómo Deleuze se ve obligado a restituir la noción de percepto en términos de imagen-percepción pero también a darle una especificidad al cine en cuanto produce como algo propio imágenesacción. $Y$, de otra parte, la imagen-tiempo, que se habría desprendido más o menos sutilmente de la pura reproducción del movimiento y de su organización en el montaje a través de la acción, para dar cuenta del tiempo 'puro' como una operación que sucede en una zona de indistinción entre la simultaneidad de los eventos del mundo percibido, las asociaciones mentales de los personajes y la particularidad con la que cada director proyecta su pensamiento a través de la organización temporal de la secuencia narrativa. Del mismo modo, tratando de dar cuenta de la variedad de las imágenes tiempo Deleuze establece una cierta analogía con la producción literaria para traer al cine ciertos 
procedimientos mentales y la capacidad que tiene la literatura para hacer perceptible lo imperceptible, de modo que al final las nociones de germen, cristal de tiempo, imagenpensamiento, o la noción misma de pregunta, van abriendo la autopoiesis propia del lenguaje cinematográfico a la vez que no dejan de evocar los modos en que ya el propio Deleuze había empezado a conceptualizar el mundo espaciotemporal como una variación heterogénea del materialismo espiritualista bergsoniano.

Hay otros ejemplos igualmente interesantes, como el paso del barroco al perspectivismo de Leibniz a través del concepto de pliegue, o la forma como la experiencia de Artaud se vuelve un prisma para entender el concepto de cuerpo sin órganos, pero en realidad esta incursión solo tenía el propósito de mostrar la vuelta 'inevitable' de Deleuze desde el territorio de la filosofía del arte al de la estética. Me explico. Si uno observa el límite al que el propio Deleuze llega en su consideración del percepto respecto de la pintura y de la imagen-tiempo respeto del cine, no es difícil adivinar que ya hay allí una inquietud ontológica acerca de la constitución del espacio tiempo en instancias que sobrepasan los límites de la percepción establecidos desde el renacimiento y organizados por Kant en relación con una noción sintética del objeto y con una concepción unificada de las facultades del sujeto. Aunque hoy es posible una lectura pluralista de las facultades (Lyotard), la herencia kantiana se define por el carácter discreto de la naturaleza y por el carácter continuo de la identidad del sujeto que conoce, desea y espera. Lo que ha hecho Deleuze es justamente poner en cuestión la unidad del objeto mostrando que la percepción no es del objeto sino de los elementos que como la fuerza, la luz, el color lo atraviesan y, por otro lado, intentando entrar en la dinámica del tiempo con una fórmula siempre inacabada entre la duración bergsoniana, el tiempo que ofrece el movimiento y la complejidad de lo que Husserl llama retenciones, protensiones y experiencias del presente vivido. La pregunta primera de los estudios sobre el cine en Deleuze tenía como objeto desentrañar la noción de duración creada por Bergson, la cual no es reductible al tiempo derivado del registro del movimiento ni al tiempo de la experiencia del sujeto. En términos analógicos, se puede afirmar que la pregunta por la duración en Bergson en cierto modo responde a la pregunta por el Ser en Heidegger. Es como si Deleuze, que nunca estuvo 
lejos de Heidegger, quisiera establecer una ontología que no dependiera de la descripción que la ciencia hace de los entes sino de la capacidad de los conceptos filosóficos para establecer como casi-causas las descripciones conceptuales que nos acercan a la dimensión de lo imperceptible.

En esa búsqueda podríamos ubicar uno de los conceptos más ricos para la estética y la filosofía del arte contemporáneas: el de ritornello. En efecto, se trata de un concepto que puede ser trasladado indistintamente de un campo a otro, a condición de que en vez de considerar la singularidad como un privilegio de las obras de arte se puedan considerar también como singulares los movimientos, las articulaciones, las velocidades, las composiciones, las intensidades en las que los diferentes seres orgánicos e inorgánicos van constituyendo el territorio. Si tierra es el concepto de la física para poder organizar ese objeto en el que vivimos, territorio es el concepto desde el que se adquiere la perspectiva vital, experimental, cotidiana de los humanos y los no-humanos. La tierra deviene territorio a través de la experiencia. Si esa experiencia es el momento visible del modo en que cada uno de los seres persiste en su ser, repetición se erige en un concepto clave para señalar la constante en la que cada uno de los seres se autoposiciona y se crea constantemente, esto es, tendríamos que aceptar que repetición y diferencia son el sístole / diástole de la constitución ontológica del mundo. Pero en lugar de ir hacia esa noción tan cercana a la de tierra, pero que finalmente resuelve la pregunta en la asunción de un concepto demasiado universal: mundo, Deleuze prefiere apostar al concepto de territorio para establecer una suerte de ontología menor que tiene su heterogénesis en el ritmo que supone el juego entre diferencia y repetición propio de cada territorio, y el cual (con Guattari) han decidido llamar ritornello.

Otra manera de abordar el territorio es reconocerlo en su composición, en sus relaciones internas, en sus imbricaciones geológicas, sin necesidad de acudir a una descripción individuada de los objetos que sobresalen en él. En plan metafísico, es como si pudiéramos despoblar el territorio para descubrir la dinámica que lo constituye en una temporalidad indescriptible en tanto que los humanos estamos por debajo del umbral de percepción del tiempo geológico. Lo podemos medir, pero no lo podemos describir como 
parte de nuestra experiencia directa. Más aún, las diferentes materias que constituyen la tierra misma parecen indiscernibles entre sí, y de esa indiscernibilidad se ha derivado un supuesto según el cual todo lo que contiene la tierra en su 'interior' es caótico, sufre de una mezcla que nunca podríamos describir adecuadamente. El pliegue es justamente la manera como Deleuze decide hacer de ese caos un cosmos posible. En ese sentido, la tierra se constituye en el constante re/des/plegamiento entre los distintos flujos y sedimentaciones de la materia. En esa heterogeneidad de materias composibles, cada pliegue es también el trazado de una suerte de piel que contiene la materia para separarla de otras, de la misma manera que ciertos tejidos contienen los órganos humanos para impedir que los fluidos se mezclen inadecuadamente unos con otros. En todo esto hay una extraña generalización de la noción de mónada pero aplicada en una diversidad de escalas tal que, no solo hacen mónada las grandes unidades que son los objetos y los individuos sino que hace mónada el torbellino y el lago y el nido del pájaro y las cuevas de las profundidades, en un proceso incesante que Deleuze llamará pliegue sobre pliegue al infinito. Esa es la versión cósmica de los alcances de la estética que siempre pareciera tener la tentación de ver el mundo como obra de arte o de instaurar en la cima de esa construcción el Dios de Leibniz, mediador par excellence del delirio cósmico deleuziano.

En realidad, lo que hace Deleuze es proponer una lectura impensable de Leibniz a partir de Nietzsche de modo que la mónada leibniziana pueda ser, primero, re/des/plegada interna y externamente $y$, a continuación, establece el plano de inmanencia en que las mónadas -sean relativas a humanos, a animales o a fenómenos naturales- puedan ser consideradas como perspectivas desde donde se constituye el mundo relativo a su propia materialidad. La mónada sería así el punto de despliegue de la perspectiva como totalización propia de cada uno de los seres y fuerzas que componen el universo. En su imbricación, esas perspectivas hacen pensar que los pliegues se definen geológicamente, pero también los pliegues se van redefiniendo en el movimiento de las diferentes sustancias que va ritmando el movimiento de la tierra sobre sí misma y, en un plano más sencillo, el juego de pliegue, despliegue y repliegue podría describir toda la riqueza de los ritornellos que acompañan la experiencia de cada uno de los seres vivos. Que la mónada 
humana tiene un centro tal que le permite captar en mucha mayor amplitud el conjunto de esos ritornellos es probable, lo que no es probable es que alguna mónada en la infinitud de su pensamiento pueda agotar en una sola mirada el conjunto de perspectivas, en tanto cada una tiene su propio vector de pliegue. Dios sería la forma en la que podríamos concebir la perspectiva de perspectivas como una totalidad, pero en este caso la noción de Dios sería una hipótesis matemática y no un concepto.

A saltos hemos hecho un recorrido que sería el de la vuelta de Deleuze al territorio de la estética y aunque parece totalmente alejado ya de la filosofía del arte no deja de ser paradójico que estos textos sobre el pliegue, el ritornello o el territorio sean los que han resultado especialmente inspiradores de muchas de las tendencias contemporáneas del arte. En la medida en que se disuelve la noción de arte como obra del artista y va ganando la idea del artista como un mediador de fuerzas, de transformaciones materiales, de intervenciones, de movimientos que están en la vida social y en la vida natural, en esa medida, el carácter pre-individual de los conceptos de Deleuze y el postulado según el cual lo singular no es propio de una obra de arte o de un individuo sino del acontecimiento mismo, en esa vía, Deleuze ha ido consiguiendo adeptos en la música, el teatro, la plástica, la literatura. También en campos específicos como el arte del cuerpo, el ecoarte, el arte localizado, el bioarte, el arte de la tierra, donde el artista ha ido perdiendo su rostro para hacer aparecer el acontecimiento dentro de una perspectiva que Amalia Boyer ha sabido nombrar como geoestética.

Los textos que van ustedes van a leer a continuación han surgido de muchas de estas preguntas y aproximaciones, con el pretexto de un seminario que devino semillero de investigación en Geoestética dentro del programa de filosofía de la Universidad del Rosario. El seminario fue planeado desde el comienzo con una premisa que era también un objetivo: entrar en el universo estético y artístico de la obra de Deleuze sin dejar de pensar continuamente en eso que a cada uno de los autores lo atrae hacia la creación, en cualquiera de sus expresiones. De ahí los ecos y las inesperadas coincidencias que plantea el dossier entre los viajes de Artaud a tierra tarahumara, la mística erótica que rodea la obra de Luis Caballero, el análisis de los videojuegos dentro del cúmulo de imágenes que 
hacen las veces de 'lo real' actualmente, la emergencia expresiva de ciertos microorganismos en experimentos controlados, la complejidad del espacio vivido en la película colombiana No futuro o el surgimiento del tango en los arrabales de Buenos Aires a comienzo del siglo XX.

El siguiente paso, en lugar de una discusión exhaustiva sobre Deleuze, consistía en trabajar con Deleuze a partir de una selección cuidadosa de los conceptos. En este punto lo importante era dar cuenta de los problemas que genera la consideración de la obra artística y los procesos creativos en su singularidad. Para ello, cada autor tuvo que encontrar un conjunto suficientemente endoconsistente de conceptos acorde con la obra misma o con el plano de expresión del que se ocupa en su investigación. Pero, finalmente, lo importante no era la obra o el plano de expresión como universos cerrados por su propia codificación crítica, sino el intento de cada autor por abrir un afuera a partir de allí: hacia su materialidad, hacia sus condiciones afectivas o sociales, hacia el universo de simulacros que puebla los paisajes urbanos a nivel global, hacia el plano de expresión de la naturaleza orgánica o inorgánica, incluso, hacia lo sublime como una instancia inapresable que trasciende la idea de estilo o de obra.

Ese afuera se presenta como el plano ontológico y estético que despierta la fuerza afirmativa de la filosofía deleuziana en nuestra experiencia del mundo contemporáneo. Se puede señalar la ausencia de un texto de referencia o la poca elaboración de un concepto, pero finalmente lo que se impuso en el ejercicio fue la idea del filósofo como un experimentador del afuera de la filosofía misma, a través del arte y la experiencia estética. En esa trayectoria hacia el afuera es donde adquiere toda su potencia la pedagogía del concepto, como le gustaba decir a Deleuze. Por eso su resultado no es puramente conceptual sino el testimonio que dejan los autores de ese abandono, seducidos por habitar el afuera que nos plantea la creación artística -más allá de la obra- y la expresión estética de la vida más allá de nuestros hábitos perceptivos o nuestros juicios sobre lo bello como animales humanos. 
